\title{
Aprendizagem e método psicanalítico
}

\section{Learning and the psychoanalytical method}

\author{
Marta Regina de Leão D’Agord ${ }^{1}$
}

\begin{abstract}
RESUMO
Este trabalho tem por objetivo contribuir para a docência universitária e como origem a seguinte questão: se o método psicanalítico estabelece princípios para uma direção de tratamento, qual seria a contribuição do mesmo para os princípios de uma direção psicanalítica de aprendizagens (ou aprendizagem?) na universidade? Trabalha-se com uma transposição do método psicanalítico, elaborado por Freud e Lacan, para o campo da aprendizagem, reconhecendo-se que o primeiro opera sobre o saber inconsciente, enquanto o segundo tem por objeto o conhecimento. As questões abordadas para a formulação de uma direção psicanalítica de aprendizagem são as seguintes: a relação entre saber e conhecimento; a relação entre o saber e o só-depois (Nachträglichkeit) e a experiência dos cartéis nas instituições de formação psicanalítica.

Palavras-chave: Método psicanalítico; aprendizagem; conhecimento; saber
\end{abstract}

\begin{abstract}
This work presents a contribution to university teaching. This study originates from the following question: if the psychoanalytical method establishes principles for a treatment direction, which would be the contribution of this method to the principles of a direction of learning in the university? This research works with a transposition of the psychoanalytical method to the field of learning, recognizing itself that the first one operates on unconscious knowing, as the second has for object knowledge. The relation between knowing and knowledge; the relation between knowing and the retroactivity (Nachträglichkeit), the experience of the institutions of psychoanalytical formation with the group called cartel are questions
\end{abstract}

1 Professora do Departamento de Psicanálise e Psicopatologia do Instituto de Psicologia da Universidade Federal do Rio Grande do Sul (UFRGS). Pesquisadora do Programa de Pós-Graduação em Psicologia Social e Institucional da UFRGS. 
to a proposal of psychoanalytical direction of learning.

Keywords: Psychoanalytical method; learning; knowledge; knowing..

\section{Aprendizagem e método psicanalítico}

\section{Introdução}

Este estudo tem por objetivo apresentar contribuições do método psicanalítico para a aprendizagem. Essa contribuição será chamada de direção psicanalítica de aprendizagem. Uma direção de aprendizagem fundada no método psicanalítico envolve, em primeiro lugar, a suposição de sujeito de um saber inconsciente. Isto é, o professor, como aquele que dirige aprendizagens, supõe um saber naqueles que se encontram em situação de aprendizagem (os estudantes). Na situação de aprendizagem, um saber inconsciente é o que determina nossas escolhas conscientes por tópicos do conhecimento. Assim, em um curso universitário no qual há possibilidade de escolha de temas para pesquisa, um determinado tema atrai o interesse de alguns estudantes. Trata-se de um tema que capta um interesse de conhecimento e com o qual o estudante se identifica. Essa identificação aponta para uma forma de relação entre o sujeito e o objeto de seu conhecimento. É essa relação que chamamos de saber inconsciente. É saber pois diz algo do sujeito, mesmo que o sujeito não tenha consciência desse saber. Em segundo lugar, essa direção de aprendizagem reconhece a temporalidade própria ao psiquismo, o só-depois, isto é, a admissão de que os acontecimentos são significados só-depois (nachträglich) ${ }^{2}$. Assim, em uma retrospectiva de sua trajetória de aprendizagens o sujeito poderá tomar consciência de uma continuidade de seu percurso e essa tomada de consciência ressignificará o próprio percurso. Essa ressignificação é um processo que acontece depois, mas que muda ou reorganiza o que aconteceu antes. Nesse sentido, saber inconsciente e só-depois são conceitos psicanalíticos que podem ser aplicados ao processo de aprendizagem.

2 O conceito de Nachträglichkeit foi traduzido em língua portuguesa, inicialmente, como “efeito retroativo” ou “posterioridade”. Através da tradução francesa como “aprés-coup” foi possível traduzi-lo, na forma adverbial e adjetiva, Nachträglich como "só-depois” e na forma substantivada Nachträglichkeit como “o só-depois”. 


\section{O saber é ou inconsciente ou pré-consciente}

Propomos, inicialmente, uma diferenciação entre saber e conhecimento. O saber será abordado como o que está inscrito na experiência de vida de uma pessoa. Enquanto que o conhecimento será tratado como o efeito de objetivação desse saber. O saber inclui desde as primeiras habilidades do bebê para identificar o que lhe dá prazer, para diferenciar e atribuir significados. No saber podemos estabelecer, então, as seguintes diferenciações: 1 . o saber intransmissível porque inconsciente; 2. o saber pré-consciente que pode ser transmitido como habilidade (o saber prévio); 3. o saber objetivado em obras e que pode ser transmitido como conhecimento. Os dois últimos são coletivizados e transmitidos. E qual seria o destino da primeira forma de saber? É justamente dessa forma de saber que a aprendizagem psicanalítica se ocupa. Essa forma de saber pode ganhar outro destino que não as formas psicopatológicas, isto é, as formas que expressam um "não querer saber nada disso". A escolha de um tema de pesquisa é um processo de destinação de um saber na medida em que essa escolha é determinada inconscientemente pela história do sujeito. Assim, os elementos inconscientes e não resolvidos de uma trajetória de vida podem ser metabolizados pelo sujeito quando inseridos em um processo de aprendizagem. E, ao longo do processo de aprendizagem, esses elementos são encadeados com novos elementos. Esse encadeamento é uma transformação, metabolização do saber inconsciente.

Para descrever o saber inconsciente, apresentaremos o caso de um sonho analisado por Freud. Um homem, que cuidara do pai durante sua última doença e ficara profundamente acabrunhado com a sua morte, teve o seguinte sonho absurdo algum tempo depois: "O pai estava vivo de novo e conversava com ele em seu estilo usual, mas ele havia realmente morrido, só que não sabia” (FREUD, 1900a/1987, p. 401).

Nesse sonho, o não saber em uma alteridade, o pai, pode ser associado ao fato de que na primeira infância, as crianças pensam que os pais sabem o que elas pensam. No momento em que descobrem que a alteridade (o Outro) pode não saber tudo, elas atingem a posição de sujeitos, tanto no sentido de se diferenciarem do Outro, como também no sentido de se tornarem sujeitos do inconsciente. Isto é, podem mentir, podem praticar o não dito e sofrer seus efeitos, o não quero nada saber disso, o inconscientizado. Pois, nesse momento, inaugura-se o não dito próprio ao saber e também ao inconsciente. Se o Outro pode nada saber, eu posso nada querer saber. Eis como podemos relacionar o não saber no Outro com a constituição do inconsciente enquanto saber insabido. Em alemão, inconscientizado e não sabido têm a mesma origem, isto é, o 
verbo saber (wissen), cuja forma negativa no particípio é unbewusste, de onde se originou o substantivo Die Unbewusste (O inconsciente).

Uma direção psicanalítica de processos de aprendizagem deve, portanto, reconhecer o saber insabido, o saber inconsciente. É pertinente aplicar o princípio psicanalítico da fala espontânea, ou seja, do falar antes, e pensar depois. Esse princípio psicanalítico transposto para a sala de aula universitária acontece quando os estudantes são solicitados a pesquisar sobre um tema de sua escolha e a desenvolver um escrito que corresponda ao seu processo de investigação. Nesse escrito, são apresentadas as primeiras questões sobre o tema, incluindo a motivação inicial, assim como as questões às quais o estudante chegou depois de um processo de investigação. Desse modo, o estudante tem a possibilidade de vivenciar um percurso singular sobre um tema. É nesse processo que o saber inconsciente é transformado. Os conteúdos escolhidos fazem o sujeito trabalhar uma questão não sabida conscientemente, mas que gerava uma interrogação. Ao final, se uma determinada pergunta, questão ou dúvida objetivada na relação com o conhecimento sofreu uma transformação ao longo da investigação do estudante, é porque o saber inconsciente se transformou no diálogo do estudante com o conhecimento. O saber insabido opera no sujeito, pois, como processo inconsciente, ele não cessa de produzir efeitos de sujeito. Quanto ao saber prévio, se trata de operar com ele, isto é, fazer das noções prévias um instrumento para desenvolvimento do conhecimento.

O que seria então o primeiro princípio de uma direção de psicanalítica de aprendizagens? O primeiro princípio pode ser assim formulado: a direção psicanalítica de aprendizagens reconhece o saber inconsciente que se transforma na medida em que o conhecimento é elaborado. Como se faz esse reconhecimento? Através da produção escrita posta à prova da alteridade, isto é, submetida aos pares.

\section{A temporalidade própria ao psiquismo: o só-depois}

Conta uma lenda africana (BASKOM, 1977) que um viajante solitário encontrou em seu caminho um crânio abandonado. - "Ora, o que faz essa cabeça aqui?", disse o viajante. Ele ficou petrificado ao escutar o crânio lhe responder: - "Ninguém se descobre envolvido num acontecimento, sem antes ter-se metido nele!” Em continuidade, o viajante relata ao chefe o que lhe aconteceu, mas o chefe solicita que três servidores acompanhem o viajante para verificar esse acontecimento. Se ele estiver mentindo, que sua cabeça lhe seja cortada. Só que 
na presença destes, o crânio nada fala e ao viajante é executada a decapitação. Quando a cabeça do viajante rola sobre a terra, o crânio fala: - "Eu bem que avisei, ninguém se descobre envolvido num acontecimento, sem antes ter-se metido nele!” e os servidores correm para relatar ao chefe o acontecimento.

Esse conto africano faz com que reflitamos sobre o que nos move nas nossas aprendizagens. As questões para as quais sempre retornamos não seriam as questões de onde sempre partimos? E essas questões têm fim?

Freud (1937/1987) aceitara o bon mot que estabelece que educar, curar e governar são três profissões impossíveis quanto às quais, de antemão, se pode estar seguro de chegar a resultados insatisfatórios. Poderíamos, então, propor que as três podem ser consideradas sob a perspectiva de uma falta, uma incompletude, algo que não termina, que não cessa de se apresentar. Um processo de aprendizagem não cessa, mas se transforma permanentemente na medida em que o sujeito descobre que há novas aprendizagens a fazer. Quando aprendemos, o objeto de conhecimento se transforma, pois descobrimos sempre novos desafios adiante. E nesse processo somos nós também que nos transformamos ao passarmos da posição de saber para a posição de não saber. Assim também acontece com um governante e um terapeuta, eles encontram novos desafios a cada etapa de suas atividades e eles também se transformam na medida em que o que antes lhes parecia satisfatório agora não o é mais.

Na obra de Freud e na obra de Lacan encontramos uma abordagem de uma forma de temporalidade que pode ser aplicada ao processo de aprendizagem analisado desde a perspectiva dos processos psíquicos inconscientes. Freud, no Projeto para uma Psicologia Científica, Freud ([1895]1950/1987) analisara essa temporalidade própria ao psiquismo a partir de um caso de histeria. Essa análise mostra o efeito de um acontecimento só-depois na formação de um sintoma histérico e as associações que operam na dissolução deste (o que pode ser comparado a um processo de desassociação). A seguir é apresentada uma versão resumida desse texto freudiano:

Emma acha-se dominada, atualmente, pela coação de não poder entrar nas lojas sozinha. Como motivo para isso, uma lembrança (cena I) da época em que tinha doze anos. Ela entrou em uma loja para comprar algo, viu dois vendedores (de um dos quais ainda se lembra) rindo juntos, e saiu correndo, tomada de uma espécie de afeto de susto. Em relação a isto, terminou recordando que os dois estavam rindo das roupas dela e que um deles lhe havia agradado sexualmente. As novas investigações revelaram uma segunda lembrança, que ela nega ter tido em mente na ocasião da cena I. Aos 8 anos de idade, ela esteve numa confeitaria em duas ocasiões para comprar doces, e, na primeira, o proprietário agarrou-lhe as partes 
genitais por cima da roupa. Apesar da primeira experiência, ela voltou lá uma segunda vez; depois parou de ir. Agora, ela recrimina-se por ter ido lá por uma segunda vez, como se com isso tivesse querido provocar a investida. [...] Haveria então um vínculo associativo entre a cena I (vendedores) e a cena II (proprietário da confeitaria), que seria o riso: o riso dos vendedores a fez lembrar-se do sorriso com que o proprietário da confeitaria acompanhou sua investida.[...] E foi essa cena I, aos doze anos, que produziu o efeito traumático, na medida em que despertou, só depois (nachträglich), a lembrança da cena que ela vivera aos 8 anos. O riso dos vendedores, que ela associou ao sorriso do proprietário da confeitaria, fez com que ela atribuísse, no relance, um sentido sexual à cena com o proprietário. (FREUD, [1895]1950/1987, p.369-370).

Uma direção psicanalítica de aprendizagens é aquela que leva em consideração a temporalidade própria ao psiquismo, tal como demonstrada por meio do caso Emma. Essa forma de estruturação temporal do psiquismo indica, para a aprendizagem, a possibilidade de releituras e significações inacabadas, infinitas, intermináveis. Um acontecimento no só-depois pode contribuir para dar sentido a um acontecimento anterior, o qual poderá estar esquecido (inconscientizado) ou não.

Em O tempo lógico e a asserção da certeza antecipada, Lacan (19451966/1998) demonstra que há uma lógica só-depois e que esta inclui o sujeito. Ou seja, se há pensamento é porque há sujeito. No artigo mencionado acima, Lacan (1945-1966/1998, p. 197) apresenta o seguinte problema de lógica:

O diretor do presídio comunica a três prisioneiros que deverá libertar um deles. Para decidir qual, submeterá os três a uma prova. Apresenta aos prisioneiros cinco discos: três brancos e dois pretos. O diretor prende um disco nas costas de cada um dos três prisioneiros. Cada prisioneiro poderá examinar o disco dos companheiros sem que seja permitida a comunicação. O primeiro que puder deduzir sua própria cor é quem será libertado. Será preciso que a conclusão seja fundamentada em lógica e não apenas em probabilidade. Para esse fim, fica convencionado que assim que um dos prisioneiros esteja pronto para formular a sua conclusão, ele transponha a porta para ser julgado por sua resposta. O diretor prende um disco branco nas costas de cada um dos três prisioneiros A referência do excerto citado já constava acima.

Lacan (1945-1966/1998) analisa a solução do problema mostrando a mo- 
dulação subjetiva do tempo por meio de três momentos de evidência, a saber, instante de olhar, tempo para compreender e o momento de concluir.

Primeira evidência: "Estando diante de dois pretos, sabe-se que é branco”. Essa formulação já apresenta desde o ponto de vista subjetivo ainda que impessoal, sob a forma do "sabe-se que..." É preciso haver o instante do olhar (que é uma instância do tempo) para que o dado se transmude: diante de dois pretos, sabe-se que se é branco.

Segunda evidência: "Se eu fosse preto, os dois brancos que estou vendo não tardariam a se reconhecer como brancos”. O sujeito aparece na intuição pela qual ele objetiva algo mais do que os dados de fato de cuja aparência lhe é oferecida nos dois brancos.

Há um tempo para compreender: Se um branco estivesse vendo um branco e um preto? E um tempo de meditação: Se eu fosse preto, ele teria saído sem esperar um instante. Se ele continua meditando é porque sou branco. Isto é, se um fosse preto-A, e um segundo poderia intuir ser um preto-B, mas se assim o fosse, o terceiro-C já teria saído para dizer-se branco, mas como estou vendo dois brancos não é possível que um terceiro veja dois pretos.

A terceira evidência: Apresso-me a me afirmar como branco, para que esses brancos, assim considerados por mim, não me precedam, reconhecendose pelo que são.

Eis aí a asserção sobre si pela qual o sujeito conclui o movimento lógico na decisão de um juízo. Não há conclusão lógica sem asserção da certeza antecipada, ou seja, a intuição, fundada na hesitação do outro, que só se torna conclusiva quando eu também, em reciprocidade, vejo-me na hesitação do outro. Essa hesitação do outro pode ser simples ou dupla. É preciso ser uma dupla hesitação para ser válida, no sentido do outro passar pelos mesmos passos que eu.

O valor lógico da terceira evidência é formulado na asserção pela qual o sujeito, já fora da sala, conclui seu movimento lógico. Trata-se de uma reflexão que acontece só-depois, isto é, um tempo para compreender subjetivo, pois é preciso lembrar que Lacan desdobrara o movimento de compreender em um modo objetivo, que se apresenta, logicamente, como a urgência do tempo para compreender e, em um modo subjetivo, que se vincula à reflexão que prossegue em um tempo só-depois.

Em sua asserção, o sujeito atinge uma verdade que será submetida à prova da dúvida, mas que ele não poderia verificar se não a atingisse, primeiramente, na certeza. Ou seja, era preciso primeiro concluir para depois refletir.

Em outras palavras, o juízo que conclui o silogismo só pode ser portado pelo sujeito que formou a asserção sobre si, e não pode ser-lhe imputado sem reservas por nenhum outro - ao contrário das relações do sujeito impessoal e do sujeito indefinido recíproco dos dois primeiros momentos, que são essen- 
cialmente transitivos, já que o sujeito pessoal do movimento lógico os assume em cada um desses momentos.

O sujeito impessoal da primeira evidência, que se exprime no "se" do "sabe-se que”, dá apenas a forma geral do sujeito noético. Na segunda evidência, “os dois brancos que devem reconhecer um ao outro”, introduz a forma do outro como tal, isto é, como pura reciprocidade, porquanto um só se reconhece no outro e só descobre o atributo que é seu na equivalência do tempo próprio de ambos. $\mathrm{O}$ [eu], sujeito da asserção conclusiva, isola-se por uma cadência de tempo lógico do outro, isto é, da relação de reciprocidade.

Esse movimento de gênese lógica do [eu] por uma decantação de seu tempo lógico próprio é bem paralelo a seu nascimento psicológico. Da mesma forma que o [eu] psicológico destaca-se de um transitivismo especular indeterminado, pela contribuição de uma tendência despertada como ciúme, o [eu] de que se trata aqui se define pela subjetivação de uma concorrência com o outro na função do tempo lógico. O que constitui a singularidade do ato de concluir é que a antecipação da certeza se confirma numa precipitação, para que, enfim, a conclusão apresente a fundamentação lógica no só-depois.

O tempo de compreender, que se inicia na segunda evidência ou segundo tempo, continua só-depois, ou seja, depois de sair da sala, depois de antecipar a conclusão. Uma conclusão seria sempre uma antecipação e a compreensão um acontecimento só-depois. Para esta pesquisa sobre a direção psicanalítica de aprendizagens, o tempo lógico interessa pelo fato mostrar que o tempo para compreender se prolonga no só-depois. Esse tempo para compreender equivaleria a uma descoberta, a uma aprendizagem.

Outra contribuição para pensar o só-depois consiste na interpretação do efeito Zeigarnik. Essa interpretação, proposta por Lacan (1954-1955/1985), nos permitirá articular o tempo lógico e a concepção de aprendizagem infinita.

O efeito Zeigarnik consiste em um achado experimental de Bluma Zeigarnik. Essa pesquisadora, aluna de Kurt Lewin, realizou em 1927 uma pesquisa que testou a proposição do sistema de tensão de Lewin. O sistema de tensão é um fator motivacional em que um determinado ato ou conjunto de atos adquire uma influência diretiva sobre o comportamento até que se dissipe. Os resultados do experimento mostraram que uma tarefa não acabada deixa um estado de tensão, uma quase-necessidade. Completar a tarefa significa resolver a tensão ou descarregar a quase-necessidade. A vantagem da memória na tarefa inacabada seria devido à continuação de tensão.

Lacan (1954-1955/1985) encontrou no efeito Zeigarnik a prova da diferenciação entre a aprendizagem animal e a aprendizagem humana. Enquanto a aprendizagem animal apresenta-se como um aperfeiçoamento organizado e finito, isto é, efeito de maturação, o efeito Zeigarnik demonstra que a aprendiza- 
gem humana se dá aos saltos, em função do desejo, o desejo de voltar às tarefas inacabadas. Lacan estabelece a seguinte comparação: “É na medida em que uma tarefa está inacabada que o sujeito volta a ela. É na medida em que um fracasso foi acerbo que o sujeito se lembra melhor dele” (1954-1955/1985, p. 115).

Assim, enquanto a aprendizagem animal é um desdobramento do que já estava inscrito biologicamente, a aprendizagem humana é reconstrução a partir de restos ou traços de lembrança, isto é, do que ficou inscrito inconscientemente. E, mesmo quando os traços de lembrança são restos da sexualidade da infância, trata-se de uma inscrição psíquica e não biológica. Ou seja, os restos de lembranças são saber inconsciente. Mas, enquanto inconsciente somente depois poderá ser percebido ou sabido. Portanto, do ponto de vista do tempo lógico, tanto o saber inconsciente como o conhecimento objetivado são processos dos quais tomamos consciência no só-depois.

Do ponto de vista fenomenológico, a elaboração enquanto compreensão de processos já vividos é um fenômeno que acontece depois de uma vivência. E a elaboração não tem prazo, ela pode acontecer muito tempo depois. Lacan denominou esse processo de tempo de compreender. Entretanto, na vida em geral, assim como na vida escolar e acadêmica, há prazos, há pressa, a vida é finita. E são esses prazos que nos levam a concluir sem haver esgotado as possibilidades de compreensão. É por isso que podemos afirmar que há uma antecipação das conclusões. O momento de concluir é uma antecipação necessária. Mas não é porque já se concluiu que cessa a compreensão. É em relação à antecipação da conclusão que a compreensão é só-depois. É em relação à finitude da conclusão que a compreensão é infinita.

O aforismo freudiano: “Wo Es war, soll Ich werden” (Onde isso era, devo eu advir) pode, então, ser aplicado a um processo no qual nos antecipamos em uma conclusão, em um fechamento da questão. Mas, o que concluímos, por exemplo, “Quem somos nós?” não se esgota em todas as aberturas de sentido que poderão surgir futuramente. E isso vale também para o conhecimento. O conhecimento que é suficiente hoje não o será amanhã.

\section{O que se pode aprender como o modelo dos jogos infinitos?}

No contexto do tratamento psicoterapêutico, Freud (1937/1987) definia a análise como uma experiência que deveria ser retomada de tempos em tempos. Ele assim explicitava que o tempo da análise não é o tempo cronológico, mas o tempo psíquico. Ele também indicava que uma análise não tem conclusão 
como o tem um curso acadêmico. Mas, e a aprendizagem que um curso acadêmico espera oportunizar, poderia ser considerada inconclusa porque infinita? A aprendizagem é processo constantemente inacabado porque sempre interrompido pelo tempo linear da organização em níveis sucessivos do dia, da semana, do semestre, do currículo acadêmico. Assim como a aprendizagem é infinita porque interminável, a análise é infinita porque interminável.

Para pensar o infinito na aprendizagem, vamos analisar em que aspectos o modelo dos jogos infinitos (CARSE, 2003) poderia contribuir. Nosso objetivo é utilizar a metáfora dos jogos infinitos para pensar a aprendizagem infinita.

Para definir jogos infinitos, Carse (2003) começa pelo jogo finito. O jogo finito tem regras e limites fixos, é jogado com o objetivo de vencer e, portanto, de acabar o jogo. $\mathrm{O}$ jogo acaba gerando um vencedor, um perdedor ou gerando o empate. O jogo finito tem um começo, tem um fim, pode terminar com empate, mas o jogo acaba. Poderá haver um outro jogo, mas já não é mais o mesmo.

Um jogo não finito não tem regras ou limites fixos. Num jogo não finito, os jogadores incluem também as regras ou os limites nos próprio jogo. O objetivo dos jogos não finitos é o de continuar o jogo.

As regras do jogo finito são externas, mas no jogo infinito elas mesmas fazem parte do jogo e só podem ser modificadas de acordo com as combinações. Os jogos finitos podem fazer parte do jogo infinito.

Os jogadores finitos tentam controlar o jogo para não ser surpreendidos pelo inesperado. Premeditam e predizem o quanto podem aquilo que vai acontecer. Estabelecem, previamente, os procedimentos, os passos e o resultado. São sérios e determinados quanto à obtenção do resultado previsto. Tentam fixar o futuro com base no passado.

Os jogadores não finitos divertem-se ao serem surpreendidos. Correndo continuamente para dentro de algo que não conhecem, aceitam que o jogo vai continuar. Para eles, a significação do passado depende daquilo que vai acontecer, de inesperado, no futuro. Os jogadores não finitos incluem as regras, as restrições ou os limites no próprio jogo. Eles os incluem como parte de seu jogo. Eles não se fixam nem às regras, nem às restrições, nem aos limites. Eles nunca podem cair na armadilha dessas regras, restrições ou limites, porque eles, para jogar, usam, no jogo, inclusive as regras e os limites.

As regras dos jogos infinitos precisam mudar durante o jogo, elas são como a gramática de uma língua viva. Nossa vida é fluida, segundo Carse (2003, p. 67), “[...] somente o que é capaz de mudar pode continuar: este é o princípio segundo o qual vivem os jogadores infinitos".

Segundo Carse (2003, p. 148), “[...] o jogador infinito dentro de nós não consome tempo, ele o gera". O jogador infinito não começa a trabalhar com o propósito de preencher um período com trabalho, e sim com a intenção de pre- 
encher o trabalho com o tempo. Enfim, o trabalho é uma maneira de engendrar a possibilidade.

Dos jogos infinitos, a direção psicanalítica de aprendizagem adota, em primeiro lugar, o princípio de que ninguém pode jogar um jogo sozinho, ninguém pode aprender sozinho. O reconhecimento da produção escrita depende de uma alteridade. Em segundo lugar, os jogos infinitos nos ensinam que podemos pensar a aprendizagem como infinita porque podemos mudar. Se não houve mudança, não houve aprendizagem.

Outra contribuição dos jogos infinitos para a direção psicanalítica de aprendizagem é a reflexão gerada pela oposição entre "preencher o tempo com trabalho" e "preencher o trabalho com o tempo". Ora, preencher o trabalho com o tempo é reconhecer a temporalidade própria ao psiquismo, isto é, reconhecer que a produção escrita estrutura-se na dimensão do tempo própria ao psiquismo.

\section{O que se pode aprender com a experiência dos cartéis?}

Na universidade, a produção escrita é valorizada não apenas enquanto autorização, isto é, autorizar-se a ser autor; mas também enquanto autoria, no sentido de se escrever a partir das próprias vivências e experiências

As vivências dos estudantes constituem um ponto de partida, as elaborações a partir dessas vivências constituem as experiências. Sobre as primeiras incide um tempo de elaboração, um tempo de compreender: e o resultado é a experiência. A produção escrita dos estudantes poderia atuar favorecendo a elaboração, favorecendo o tempo de compreender?

Lacan (1966/1998), na abertura dos Escritos, retoma o adágio de Buffon (1707-1788), segundo o qual “o estilo é o próprio homem”. Ora, se há estilo é porque há sujeito da escrita. Assim, é possível considerar que todo escrito contenha o estilo do autor.

Na recitação do que já foi enunciado pelos autores, aqueles que recitam não se reconhecem como autores, mas como epígonos. Ora, teria sido na tentativa de driblar o aparecimento da prática epigonal dentro da própria instituição psicanalítica que Lacan teria proposto a atividade de cartéis? A partir dessa questão vamos analisar se é possível encontrar relações entre as propostas dos cartéis e de direção psicanalítica de aprendizagem.

No “Ato de fundação” da Escola Freudiana de Paris, Lacan (1964/2003) apresentou o cartel como um método de trabalho em pequeno grupo. 
Os que vierem para esta Escola se comprometerão a cumprir uma tarefa sujeita a um controle interno e externo. [...] Para a execução do trabalho, adotaremos o princípio de uma elaboração apoiada num pequeno grupo. Cada um deles se comporá de no mínimo três pessoas e no máximo cinco, sendo quatro a justa medida. MAIS UM encarregado da seleção, da discussão e do destino a ser reservado ao trabalho de cada um. Após um certo tempo de funcionamento, os componentes de um grupo verão ser-lhes proposta a permuta para outro. (LACAN, 1964/2003, p. 235).

A palavra cartel nos remete às seguintes relações: O número quatro formando uma estrutura de enlaçamento borromeano: um entrelaçamento de anéis tal que, basta abrir um deles para que todos fiquem soltos e o enlace desapareça. Uma carta enviada como desafio; uma provocação, cuja etimologia, segundo o dicionário Houaiss, remete ao francês cartel (1527) como carta de desafio para duelo.

O modo de funcionamento dos cartéis conduziu Lacan (apud JIMENEZ, 1994, p. 15) a acrescentar as seguintes indicações:

\begin{abstract}
Em primeiro lugar: quatro se escolhem para prosseguirem um trabalho que deve ter seu produto. Dou a precisão: produto próprio a cada um, e não coletivo. Em segundo lugar: a conjunção dos quatro se faz em torno de um mais-um, que, sendo qualquer um, deve ser alguém. Cabe a ele o encargo de velar pelos efeitos internos da empresa e de provocar sua elaboração (um dos professores escolhido pelo cartel). Em terceiro lugar: para prevenir os efeitos de cola (grude), uma permutação deve ser feita no prazo fixo de um ano, dois no máximo. Em quarto lugar: nenhum progresso é esperado senão o de uma exposição periódica a céu aberto dos resultados assim como das crises de trabalho.
\end{abstract}

A função do mais-um vem a ser a de provocação à elaboração. O mais-um provoca a produção, mas não é professor, líder ou coordenador de grupo. Ou seja, ele não está implicado como membro do grupo, por isso não é seu líder nem coordenador. Ele não tem por função controlar a aprendizagem ou ensinar, por isso não é professor. A função do mais-um seria um modelo de direção de aprendizagens, isto é, a função de conduzir processos, mas não pessoas.

O que reúne um grupo de pessoas em um cartel não é a amizade entre os participantes, mas a afinidade do projeto comum, o tema ou objeto de investigação. A função do diretor de aprendizagens e a função do mais-um preservam 
a autonomia organizativa dos participantes. O diretor de aprendizagens dirige os processos de investigação, e não exerce funções de professor, assim também no cartel, o mais-um, tem por função provocar, no sentido de suscitar, a elaboração dos temas.

Os grupos de aprendizagem sintetizam as caraterísticas de finitude e infinitude dos cartéis. A finitude dos cartéis era marcada pela antecipação de sua dissolução, pois estava previsto, na proposta de Lacan, que esses se dissolveriam depois de concluída a produção de cada participante. Cada participante endereçaria, então, novas questões a novos participantes, formando novos cartéis com outros mais-um. Esse segundo aspecto descreveria a característica de infinitude. Assim, o processo de produção escrita era interrompido (finitude) e continuado (infinitude) em outro momento. Enquanto que a alteridade, a parceria, era permutável. Essa permuta tinha o objetivo de quebrar a continuidade do mútuo entendimento imaginário, possibilitando aos participantes o encontro de outros leitores de suas produções escritas.

\section{A direção psicanalítica de aprendizagens}

A direção psicanalítica de aprendizagens na universidade sustenta-se em alguns princípios analisados acima. Vamos retomá-los articulados entre si. Saber é saber inconsciente ou pré-consciente. Conhecimento é saber objetivado. Há saber insabido porque inconsciente. Assim como há saber não sabido porque ainda não se elaborou suficientemente, há sempre restos a elaborar. E essa elaboração é infinita porque sempre inacabada. Ao adotarmos o princípio da temporalidade própria ao psiquismo, o tempo de compreender aproximou conhecimento e saber. Pois ambos são inacabados em relação ao tempo de compreender. O conhecimento é objetivado no só-depois. E o saber inconsciente só-depois é saber propriamente dito, ou seja, primeiro é ato inconsciente, só-depois é saber. $\mathrm{O}$ que distingue ambas as formas é que o primeiro opera conscientemente, a explicação é necessariamente um processo consciente e o segundo opera inconscientemente.

A temporalidade própria ao psiquismo poderá ser reconhecida no âmbito universitário? Sem dúvida, desde que o término do semestre não seja identificado a um término do estudo de um tema, mas a uma interrupção ou a um reencaminhamento de estudos. Dessa forma, as interrupções e reencaminhamentos de temas e questões podem seguir o ritmo dos semestres universitários sem prejuízo da infinitude da aprendizagem. Um texto em processo de escrita sempre poderá 
ser retomado ou aperfeiçoado em outro momento.

Seguir princípios da direção psicanalítica de aprendizagens é também reconhecer esses limites, é saber trabalhar os limites que nos constituem. Um escrito ou um projeto não se encerra em um semestre, mas pode ser interrompido. Isso não impede que, no só-depois, o tempo de compreender continue operando e que o saber não sabido, assim como o conhecimento, sejam retomados. Isso significa que a aprendizagem é um processo sempre inacabado ou infinito que está sempre por acontecer, inclusive em circunstâncias regidas pelo tempo cronológico.

\section{REFERÊNCIAS}

BASKOM, M. African Folktales in America. The talking skull refuses to talk. Research in African Literatures 8/2, Univ. of Texas., 1977. Disponível em: <http://perso.orange. fr/espace.freud/crane.htm>. Acesso em: 24/04/2007.

CARSE, J. P. Jogos finitos e infinitos. Rio de Janeiro: Nova Era, 2003.

FREUD, S. Studienausgabe. Frankfurt a. Main: Fischer, 1972.

. Projeto para uma psicologia Científica. Edição Standard brasileira das obras psicológicas completas de Sigmund Freud. v. I. Rio de Janeiro: Imago, 1895-1950/1987. p. 303-409.

. A Interpretação dos Sonhos. Edição Standard brasileira das obras psicológicas completas de Sigmund Freud. v. V. Rio de Janeiro: Imago, 1900a/1987. p. 323-667.

Análise terminável e interminável. Edição Standard brasileira das obras psicológicas completas de Sigmund Freud. v. XXIII. Rio de Janeiro: Imago, 1937/1987. p. 241-287.

HOUAISS, A. Dicionário eletrônico da língua portuguesa. Rio de Janeiro: Objetiva, 2002. 1 CD-ROM.

JIMENEZ, S. (Org.). O cartel: conceito e funcionamento na escola de Lacan. Rio de Janeiro: Campus, 1994.

LACAN, J. O Seminário: livro 2: o eu na teoria de Freud e na técnica da psicanálise. Rio de Janeiro: Jorge Zahar, 1954-1955/1985.

. Escritos. Rio de Janeiro: Jorge Zahar, 1966/1998. 
Ato de fundação. In: . Outros escritos. Rio de Janeiro: Jorge Zahar, 1964/2003. p. 235-247.

. Proposição de 9 de outubro de 1967 sobre o psicanalista de Escola. In:

Outros Escritos. Rio de Janeiro: Jorge Zahar, 1967/2003. p. 248-264.

Texto recebido em 15 de maio de 2008.

Texto aprovado em 6 de junho de 2009. 